\title{
The strong and the weak: evaluation in modal desideratives
}

\author{
Erin Zaroukian \& Charley Beller*
}

LSA Annual Meeting, Minneapolis, January 2-5, 2014

1. Introduction. This paper investigates two desiderative interpretations generated by modal auxiliaries. The first, which we term strong desiderativity, has two defining characteristics: (1) it involves strict preference (>) of one situation over another (see e.g. Heim, 1992; Villalta, 2008; Iatridou, 2000), and (2) it is felicitous out of the blue. Strong desiderativity can result when the modal would appears with evaluatives such as like, as well as from from lexical desideratives like want (Beller and Zaroukian, 2012). ${ }^{1}$

I $\left\{\begin{array}{c}\text { want } \\ \text { would like }\end{array}\right\}$ a cookie.

'A situation similar to this one but wherein I have a cookie is preferable to this situation'

$$
\text { (A: Cookie anyone? ) B: I }\left\{\begin{array}{c}
\text { want } \\
\text { would like }
\end{array}\right\} \text { a cookie. }
$$

The second interpretation, which we term weak desiderativity, likewise has two defining characteristics: it indicates that one situation is at least as good as another $(\geq)$, and it is infelicitous out of the blue. Would and might yield weak desiderative interpretations with canonical-use verbs and also with underspecified-use verbs like have and take.

$$
\text { \#(A: Cookie anyone? ) B: I }\left\{\begin{array}{c}
\text { would } \\
\text { might }
\end{array}\right\}\left\{\begin{array}{c}
\text { have } \\
\text { take } \\
\text { eat }
\end{array}\right\} \text { a cookie. }
$$

We provide an analysis that accounts for the data above by introducing a comparison operator and a criterion determining how alternative situations are introduced for comparison. We propose that a comparison operator is part of the present subjunctive morpheme (cf. Villalta, 2008), which we assume to be part of the modal auxiliaries would and might. ${ }^{2}$ Additionally, alternatives are introduced in strong desideratives by evaluative elements (e.g. like).

2. Comparison. We assume that comparison in strong and weak desideratives is introduced via subjunctive morphology (cf. Villalta, 2008), and that this subjunctive morpheme is part of would and might.

* Many thanks go out to the Johns Hopkins University Semantics Lab. This research was facilitated by grants ANR-10-LABX-0087 IEC and ANR-10-IDEX-0001-02 PSL. Authors: Erin Zaroukian, École Normale Supérieure/CNRS (egz@jhu.edu) \& Charley Beller, Johns Hopkins University (charleybeller@jhu.edu).

${ }^{1}$ N.B. We are talking about requests/desire reports, not counterfactual or other readings (e.g. I would like this lasagna if it had less cheese, I might take Biology next year).

${ }^{2}$ Weak desideratives can also be formed with could. The data is more complicated with this modal auxiliary, however, so we do not include it in this paper. 
2.1. Strong Desideratives. We adopt the view that desideratives express a comparison (Heim, 1992; Villalta, 2008, i.a.). For example, the strong desiderative I want a cookie raises the issue that, in the speaker's view, the addition of a cookie to the current situation would improve it (now + cookie $>_{s}$ now). The comparison operator is introduced through a

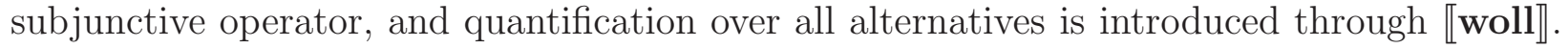
This comparison and quantification are present with the strong desiderative want (Heim,

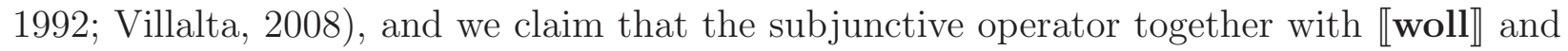
an evaluative verb (e.g. like) also form a strong desiderative.

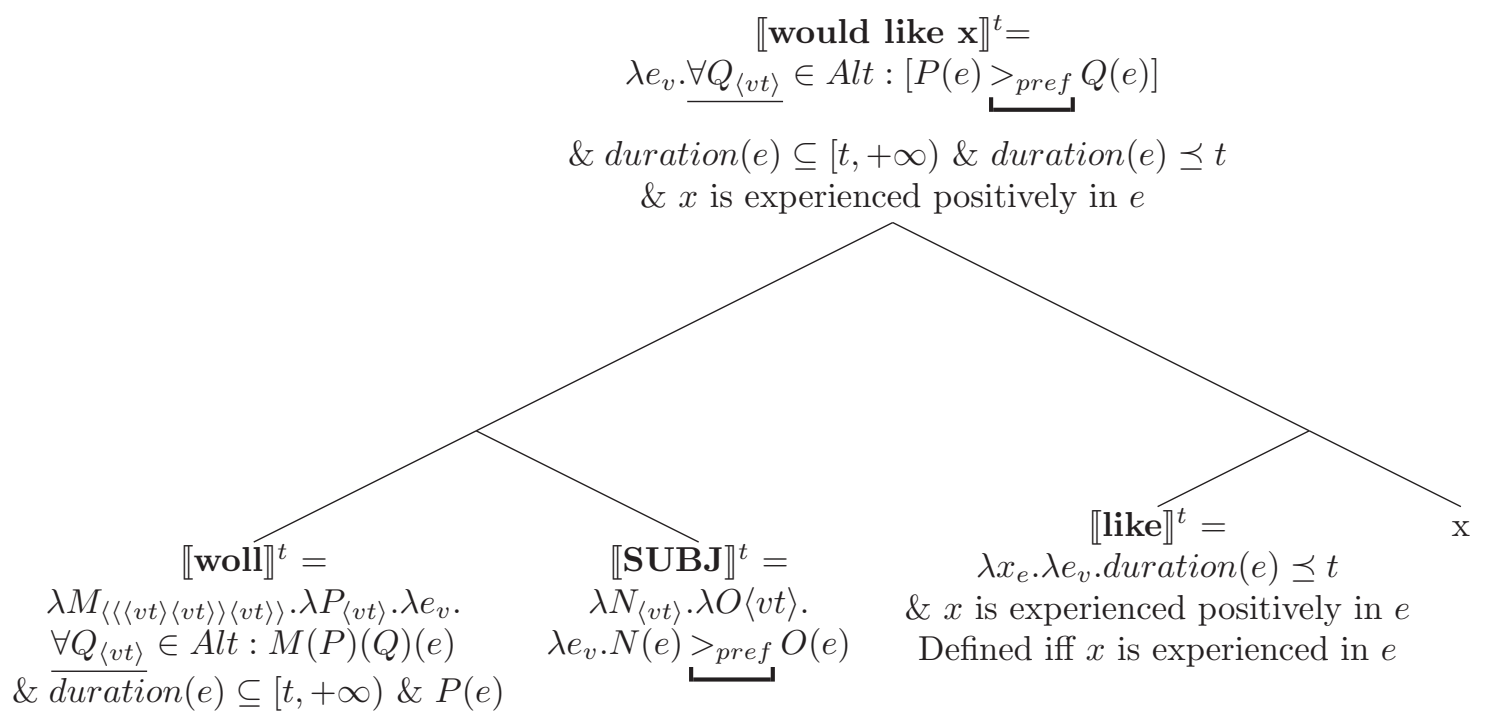

2.2. Weak Desideratives. Might has a weaker (existential) quantificational force than would, leading to what we call a weak preference.

$$
\begin{aligned}
& \llbracket \operatorname{may} \rrbracket^{t}=\lambda M_{\langle\langle\langle v t\rangle\langle v t\rangle\rangle t\rangle} \cdot \lambda P_{\langle v t\rangle} \cdot \lambda e_{v} \cdot \underline{\exists Q_{\langle v t\rangle}} \in \operatorname{Alt}: M(P)(Q) \& \text { duration }(e) \subseteq[t,+\infty) \\
& \& P(e) \\
& \quad(\text { cf. Condoravdi, 2003) }
\end{aligned}
$$

We propose that existential modals cannot lead to strong desiderativity; knowing that something is preferred to at least one alternative is not forceful enough to yield a request reading, cf. (6).

a. I would feel better if you let me drive.

$(\forall$, can be request)

b. It's possible that I would feel better if you let me drive. ( $\exists>\forall$, not a request)

While the utterances in (7) contain would (i.e. a subjunctive operator to introduce

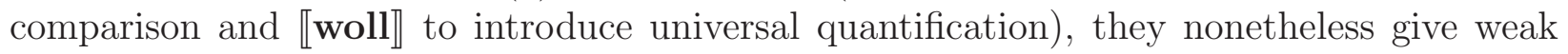
desiderative readings.

$$
\text { I would }\left\{\begin{array}{c}
\text { have } \\
\text { take } \\
\text { eat }
\end{array}\right\} \text { a cookie. }
$$


The explanation, we propose, lies in how alternatives are introduced for comparison.

3. Introducing alternatives. Recall that only strong desideratives are felicitous as requests out of the blue. Above we claimed that auxiliaries with existential force (might) are too weak to form request. Here we argue that, beyond, this, relevant alternatives for comparison must be available. Evaluative verbs (e.g. like), as well as the desiderative want, convey privileged information about an agent's preferences. We propose that an (appropriate) evaluative verb is needed to introduce alternatives out of the blue. Strong desiderativity thus results when a modal (which, as shown above, must be would, i.e. have universal force and contain a subjunctive operator) combines with an evaluative, which can introduce potential alternatives.

(8) I $\left\{\begin{array}{c}\text { want } \\ \text { would like }\end{array}\right\}$ a cookie.

(strong desideratives)

Recall that desideratives with existential force express only weak preference and cannot act as requests, they can only accept offers.
A: Anybody want a cookie?
B: I might $\left\{\begin{array}{c}\text { have } \\ \text { take } \\ \text { eat } \\ \text { like }\end{array}\right\}$ a cookie.
(weak desideratives)

Here we claimed that if no evaluative verb is involved, something else in the discourse (e.g. a relevant question) must introduce alternative desirable situations.

$$
\begin{aligned}
& \text { A: Anybody want a cookie? } \\
& \text { B: I would }\left\{\begin{array}{c}
\text { have } \\
\text { take } \\
\text { eat }
\end{array}\right\} \text { a cookie. }
\end{aligned}
$$

4. Conclusion. In this paper, we utilized a comparison operator and a criterion determining how alternative situations are introduced. Specifically, we assumed would and might here have present subjunctive morphology, which introduces a comparison operator (cf. Villalta, 2008), and we proposed that this operator is $>$, which is weakened in force with existential modals (might, could) such that it cannot act as a request. Finally, weak desideratives do not contain an evaluative verb and therefore require that the desirable alternatives be already salient in the discourse.

This analysis shows an important and novel role of evaluative predicates in constraining discourse function, and it may have ramifications in the wider domain of preference structures (imperatives, desire reports, etc.), particularly concerning strong/weak necessity (Portner, 2007; Rubenstein, 2013, a.o.). 


\section{References}

Beller, Charles, and Erin Zaroukian. 2012. Stage-level evaluativity is desiderativity. In Proceedings of Sinn und Bedeutung 16, ed. A. Aguilar-Guevara and A. Chernilovskaya, MIT Working Papers in Linguistics, 71-84. Cambridge, MA: MIT Press.

Condoravdi, Cleo. 2003. Moods and modalities for will and would. Handout of talk presented at the Amsterdam Colloquium.

Heim, Irene. 1992. Presupposition projection and the semantics of attitude verbs. Journal of Semantics 9:183-221.

Iatridou, Sabine. 2000. The grammatical ingredients of counterfactuality. Linguistic Inquiry 31:231-270.

Portner, Paul. 2007. Imperatives and modals. Natural Language Semantics 15:351-383.

Rubenstein, Aynat. 2013. Figuring out what we ought to do: the challenge of delineating priorities. In University of Pennsylvania working papers in lingusitics, volume 19: Iss. 1, Article 20. Available at: http://repository.upenn.edu/pwpl/vol19/iss1/20.

Villalta, Elisabeth. 2008. Mood and gradability: an investigation of the subjunctive mood in Spanish. Linguistics and Philosophy 31:467-522. 